\title{
Problems and Countermeasures of Internal Audit Quality Control in Chinese Enterprises
}

Lin Tang*

Tongling University, Tongling 244061, China. E-mail: 1945298495@qq.com

\begin{abstract}
With the development of society, enterprises in China has become an indispensable pillar, and much attention has been paid to the quality control of internal audit. Under the background of research on enterprise internal audit quality control, this paper expounds the importance of enterprise internal audit quality in strengthening management norms, maximizing enterprise interests and maintaining the enterprise's own reputation. The shortcomings and problems of enterprise internal audit quality are analyzed. It also puts forward some solutions around the low comprehensive quality of personnel, the lack of independence of audit institutions, imrigorous review procedures, imperfect laws and regulations and so on.
\end{abstract}

Keywords: Internal Audit; Quality Control; Problems and Countermeasures

In recent years, China's capital market is becoming more and more developed, and at the same time, a growing number of people begin to pay attention to the financial statements and audit reports of enterprises. However, audit scandals such as audit mistakes or audit fraud not only make investors suffer losses, but also expose that under the modern enterprise system, the problem of internal audit quality control is still very serious ${ }^{[1]}$.

\section{The importance of internal audit quality in enterprises}

It is extremely crucial for enterprises to attach importance to audit quality control, which is of great significance for them to improve standardized management, interests and their own reputation.

\subsection{It is beneficial for enterprises to strengthen management norms}

Audit quality control is an important means to ensure that independent audit standards are complied with and implemented ${ }^{[2]}$. Without quality control, the application of independent audit standards can only be a mere formality. It can not reasonably find out the specific problems within the enterprise and achieve the desired purpose of the enterprise. Therefore, audit quality control has become one of the momentous factors for enterprises to strengthen management norms.

\subsection{It is beneficial to maximize the interests of enterprises}

Through the previous control, during and after the event, the internal audit can reasonably and effectively detect the risks existing in the business process. Internal audit also finds out the ways to deal with these risks in advance to reduce the investment risk as much as possible to a the bearable level, which can maximize the interests of the enterprise.

\footnotetext{
Copyright (C) 2020 Lin Tang doi: $10.18686 /$ aat.v2i2.1320

This is an open-access article distributed under the terms of the Creative Commons Attribution Non-Commercial License (http://creativecommons.org/licenses/by-nc/4.0/), which permits unrestricted non-commercial use, distribution, and reproduction in any medium, provided the original work is properly cited.
} 


\subsection{It is beneficial for enterprises to maintain their own reputation}

Through internal audit, enterprises put forward effective decisions to meet the needs of service objects. These decisions can further harmonize the working relationship between audit and being audited, audit and senior management, so as to improve the feasibility of decision-making and help to maintain their own reputation.

\section{Quality control of internal audit in enterprises}

Although there are so many advantages, there are still some problems, such as low quality of personnel, lack of independence of audit institutions, imrigorous review procedures, imperfect laws and regulations, and so on ${ }^{[3]}$.

\subsection{The comprehensive quality of personnel is low}

With the development of socialist market economy, Chinese enterprises are developing so rapidly that have become an important support for the development of national economy. At the same time, enterprise internal audit also needs to be further improved. However, the comprehensive qualities such as working experience and professional ethics of employees in our country still need to be improved. The auditors of most enterprises are transferred from the accounting profession. They are more good at financial audit knowledge, but lack of the concept of modern enterprise operation and management. They have limited knowledge reservation and weak, professional skills ${ }^{[4]}$. Moreover, it is possible for auditors to be disturbed by external factors, such as being tempted by potential interests to do something harmful to professional ethics. All these are not conducive to enterprises to make correct decisions.

\subsection{Lack of independence of audit institutions}

Independence is closely related to the objectivity and impartiality of internal audit. Only on the premise of ensuring independence can the internal audit department and internal auditors draw objective and fair audit conclusions about the actual operating conditions of the enterprise. Most of the enterprises in our country are mainly small and medium-sized enterprises, so the operation scale of most enterprises is not very large, and the internal audit is not generally an independent department, but merged with other departments ${ }^{[5]}$. Some subordinate to the financial and accounting departments of enterprises, lack of independence, can only meet the needs of managers as far as possible. Therefore the audit results will have a strong subjective color, which is the embodiment of personal will. This is not conducive to the control of audit quality.

\subsection{The review procedure is not rigorous}

Audit review is a typical ex post control. In the process of review, the reviewers consult the feedback of the auditees on their audit applications and draw a conclusion. Among them, there are not enough direct communications with the audited units, so it is difficult to fully and clearly reflect the causes of the problems from the point of view of the audited units, which is not conducive to the reviewers to make a comprehensive and objective judgment on the review materials. At the same time, the time lag of the review procedure, the inoperability of the procedure, and the imperfect organization and personnel will affect the rigor of the review procedure.

\subsection{Laws and regulations are not perfect}

The law is the basis of the audit work. If the legal system is not complete or linked, the auditors will lose the unified judgment standards, increasing the risk opportunity. However, at present, there is still a situation in China that the audit laws and regulations are not perfect and the legal provisions are not detailed. It is divided into the following points: (1) Inaccurate qualitative audit facts. If the audit finds out the same type of problems, because the qualitative standards are inconsistent and inconsistent, it will cause the qualitative inaccuracy of the audit facts, thus affecting the operation of the enterprise. (2) The conflict of laws rules are not applied correctly. For example, the special law should be applied to the general law, and the new legal norms should be applied in connection with the old law, and the renewal effect is not significant, and so on ${ }^{[6]}$. 


\section{Countermeasures for quality control of internal audit in enterprises}

In view of the problems existing in the above-mentioned enterprise internal audit, some solutions are also put forward.

\subsection{Strengthen the cultivation of personnel's comprehensive quality}

The audit quality of enterprises is inseparable from the comprehensive quality of staffs. The comprehensive quality of auditors determines the audit quality of enterprises. First of all, enterprises should appropriately increase the salary of audit and guide staff to establish the relevant awareness of audit quality control, so as to improve their professional ability, to a certain extent, which can also curb the occurrence of bribery. Secondly, enterprises should attach importance to the selection of compound talents through multiple channels by carrying out irregular workplace training, on-the-job training, professional ethics training and reward and punishment system, so as to strengthen the comprehensive quality of personnel ${ }^{[7]}$. Finally, staffs themselves should also improve their moral literacy and professional ability and actively learn how to effectively and reasonably strengthen audit quality control.

\subsection{Establish a reasonable internal audit institution}

Independence affects the objectivity and impartiality of internal audit to a certain extent. It is necessary to establish a reasonable internal audit institution with a high degree of independence. Internal audit institutions can independently exercise audit functions and powers without being restricted by other departments, managers and individuals, which has reflected the objectivity, impartiality and effectiveness of audit ${ }^{[8]}$.

\subsection{Strict audit procedure}

The quality of audit procedures will also affect audit quality control. So we have to strictly set up audit procedures. On the one hand, we can innovate the review mechanism by changing the "review lag" to "review pre-position", so as to guard against risks in a timely manner. Besides, breaking the traditional way of written inspection, communicating with the auditees as much as possible, and earnestly considering the position of the auditees are also crucial. On the other hand, it is also necessary to improve the review institutions, equip professional personnel, and strict audit procedures.

\subsection{Improve laws and regulations}

The control of enterprise audit quality needs not only the effective improvement of the internal environment, but also the improvement of the external environment ${ }^{[9]}$. For example, enterprises should improve the relevant laws and regulations on audit quality and the legal provisions to form a complete legal system. Auditors are provided with unified judgment standards to reduce risk opportunities. The state should affirm the inaccuracy of qualitative audit facts. When finding out the same type of problems, we should provide auditors with reasonable and unified qualitative standards to accurately determine the audit facts, which can improve the audit quality and accuracy of correctly applying the rules of conflict of laws. The special law, the general law, the new law and the old law all provide a clear definition, which is convenient for auditors to make feedback and reduce the risk of the enterprise ${ }^{[10]}$.

\section{Conclusion}

To sum up, the development of enterprises is inseparable from internal audit. At present, the quality control of internal audit may not be particularly perfect, and there are still many problems, such as low comprehensive quality of personnel, low independence of audit institutions, imrigorous review procedures, imperfect laws and regulations, and so on. However, it can also be amended from the aspects of improving the comprehensive quality of personnel, establishing reasonable internal audit institutions, strict audit procedures, perfecting laws and regulations, and so on. It is believed that in the near future, the quality control of internal audit will be greatly improved, and the enterprise will be more outstanding and brilliant. 


\section{References}

1. Liu W. Problems and countermeasures in internal audit of small and medium-sized enterprises (in Chinese). Market Modernization 2016; (26): 188-189. doi: 10.3969/j.issn.1006-3102.2016.26.105.

2. Zhou D. Research on internal audit quality control of Chinese enterprises (in Chinese). Contemporary Economics 2012; (8): 130-131. doi: 10.3969/j.issn.1007-9378.2012.08.063.

3. Zhao Y. RH accounting firm research on the problem of audit quality control [Master thesis]. Shenyang: Liaoning University; 2014. p. 54-65.

4. Liu B. Problems existing in enterprise internal audit quality control and countermeasures (in Chinese). Foreign Investment in China 2013; 3(128): 161-164.

5. Yin J. Talking about the quality control of enterprise internal audit (in Chinese). Accounting Learning 2017; (11): $130-131$.

6. Zhao Z, Zhang X, Chen H. Internal audit quality control strategy. Communication of Finance and Accounting 2014; (4): 84-86.

7. Hu H. Research on the problems and countermeasures of internal audit quality control in Chinese enterprises (in Chinese). Market Modernization 2012; (694): 54-55.

8. Su Y. A company internal audit quality control research (in Chinese). 2016; 186-189.

9. Fan J. Investigation on the evaluation index system of internal audit quality control based on the balanced score card. Auditing Research 2013; (2): 82-89.

10. Yu Q. Analysis of the current status and countermeasures of internal audit quality control in Chinese enterprises. Science \& Technology Information 2015; (9): 139. doi: 10.3969/j.issn.1672-3791.2015.09.117. 